\title{
Landslides and synoptic weather trends in the European Alps
}

\author{
J. L. Wood $^{1}$ • S. Harrison ${ }^{1}$ - T. A. R. Turkington ${ }^{2}$ • \\ L. Reinhardt ${ }^{1}$
}

Received: 12 May 2015 / Accepted: 31 January 2016 / Published online: 27 February 2016

(C) The Author(s) 2016. This article is published with open access at Springerlink.com

\begin{abstract}
Landslides present a substantial geomorphological hazard in Alpine regions and there are expectations that climate change will alter their frequency and magnitude in the future. Understanding the spatial distribution and timing of landslides in the context of past change is therefore necessary if we are to assess their future behaviour. Using a regional landslide inventory for the European Alps we analyse the influence of weather types, specifically the COST733 database, on landslides. Monte Carlo permutation tests are used to assess which weather types are most likely associated with landslides. Weather types with high precipitation are consistent with more landslides, although there are also seasonal differences. Over the duration of the COST733 catalogue there has been a significant decrease in the number of days with weather types associated with low frequencies of landslides. During the spring and autumn months, the trend in observed landslide frequency and weather types are well matched. However while there is potential for weather typing to be used as a proxy for future landslide frequency, other external factors must be carefully considered.
\end{abstract}

\section{Introduction}

Landslides are a serious geomorphological hazard in many of the world's mountain regions (Keiler et al. 2010; Malet et al. 2010). In the European Alps, population and infrastructure growth provides the impetus for better understanding of the pattern of landsliding, triggers, and efforts required to reduce landslide risk. The climate of the region is changing, and this has

Electronic supplementary material The online version of this article (doi:10.1007/s10584-016-1623-3) contains supplementary material, which is available to authorized users.

\section{J. L. Wood}

J.L.Wood@Exeter.ac.uk

1 College of Life and Environmental Sciences, University of Exeter, Exeter, UK

2 Faculty of Geo-Information Science and Earth Observation, University of Twente, Enschede, Netherlands 
been implicated in increased landslide risk (Borgatti and Soldati 2010; Crozier 2010; Keiler et al. 2010). While understanding the spatial distribution of past landslides can help to facilitate better understanding of regional landslide impacts and triggers, such an analysis can only be obtained through the use of regional-scale landslide inventories.

Landslides are triggered by a number of factors, including earthquakes (Keefer 2002; Malamud et al. 2004; Meunier et al. 2008), rainfall (Iverson 2000; Zêzere et al. 2005; Guzzetti et al. 2007; Keefer and Larsen 2007; Marques et al. 2008), temperature change (Dehn and Buma 1999; Chemenda et al. 2005), glacial recession and permafrost degradation (Dramis et al. 1995; Stoffel et al. 2014) and anthropogenic factors such as the removal of slope toes at road cuts (Barnard et al. 2001). For landslides, the hydro-meteorological trigger is often rainfall (Jakob and Weatherly 2003; Farahmand and Aghakouchak 2013), and empirical rainfall thresholds are often used to define minimum triggering conditions for landslides (Peruccacci et al. 2012); however these are often localized, and depend greatly on the quality of rainfall data (Gariano et al. 2015). The use of broader scale atmospheric conditions can alleviate this problem although, to date, few studies have addressed this issue (e.g. Nikolopoulos et al. 2015).

Synoptic weather types provide a way in which to classify atmospheric circulation into a number of discrete types, providing a widely used tool for analysing weather and climate conditions. Synoptic weather types have also been proposed as an effective method of downscaling Global Climate Model outputs (Conway and Jones 1998). A number of authors have noted that the proportion of weather types can change over time, with different circulation patterns becoming more (or less) frequent. Paredes et al. (2006) found a decrease in March weather types, in the Iberian Peninsula, that were major rainfall contributors, matched with $50 \%$ decline in accumulated precipitation for the period 1960-97, whilst Boé and Terray (2008) found a difference in the frequency of weather types in France over the 20th Century, producing an increase in precipitation in northern France, and a decrease in the South. Under a changing climate, it is probable that the proportion of weather types in regions, such as the European Alps, has and will change in the future (Lopez Saez et al. 2013).

This paper assesses the links between synoptic weather types and landslide occurrence. Using the ERA40 reanalysis dataset provided by the European Centre for Medium-Range Weather Forecasts (Uppala et al. 2005), the European Cooperation in Science and Technology Action 733 (COST733) provides a classification catalogue for synoptic weather in Europe (from September 1957 to August 2002; Philipp et al. 2010). Using this catalogue alongside the landslide inventory for the European Alps (Wood et al. 2015), the temporal and spatial distribution of landslides and historical trends in weather types are analysed. Given that weather typing has been shown to be an appropriate downscaling tool for climate models (Conway and Jones 1998), we hope that this research will help to pave the way to assessing future landslide hazard in the region through the use of future climate scenarios.

\section{Methods}

\subsection{Landslide inventory}

The landslide inventory used covers the French and Swiss portion of the European Alps (Fig. 1a) and is a collation of existing inventories from academic, national online datasets, research institutes and from the insurance industry (Wood et al. 2015). There are a total of 

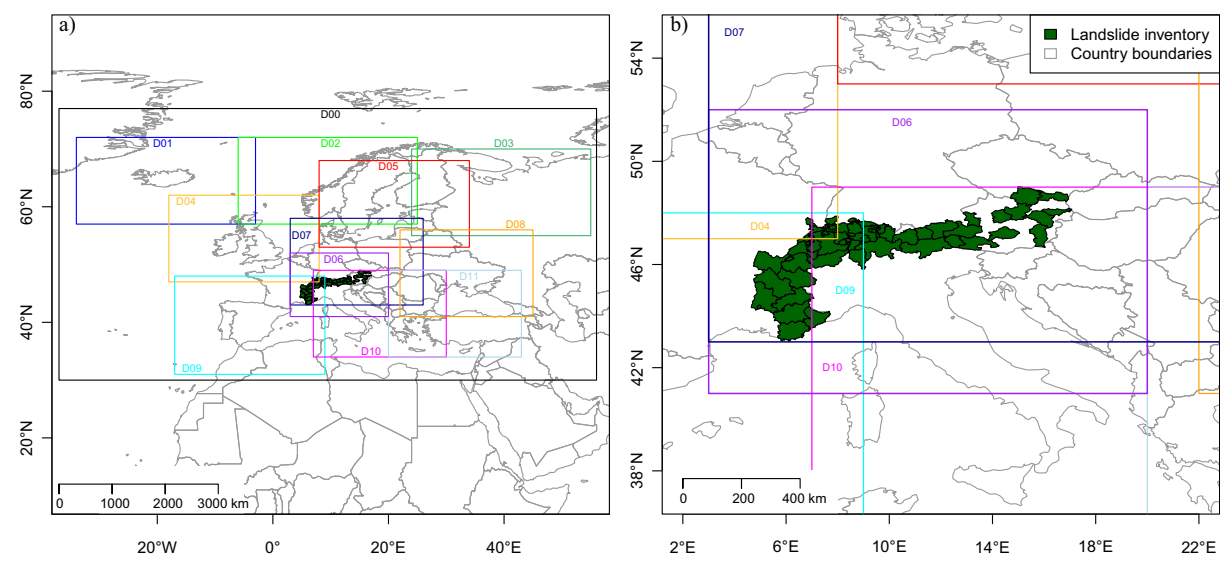

Fig. 1 a The COST733 catalogue, subdivided into 12 domains (D00 to D11), covering a range of regions at different spatial scales, from the whole of the Europe s (D00) down to smaller regions such as the European Alps (D06). b The extent of the landslide inventory (green) and COST733 domains, which cover all (D06 and D07) or a portion (D04, D09 and D10) of the area included in the inventory

7919 records in the inventory, of which 5040 include landslide location and exact date of occurrence. Landslides in the inventory are classified according to Varnes (1978) classification system; 31 remain unclassified, 744 are rock falls, slides and topples, 254 recorded mud/debris flows and 59 complex landslides with the remaining 3952 rotational or translational landslides (henceforth referred to as 'landslides'; Wood et al. 2015). It is due to the scarcity of data in the other classes that only rotational and translational landslides are considered in this study. Based on magnitude/frequency statistics (Malamud et al. 2004) the post-1970 portion of the inventory is considered to be most complete (Wood et al. 2015), and so this portion of the inventory (2966 landslides) is used in this study. Given the incidence of seismic activity in the European Alps, the inventory was assessed for earthquake-triggered landslides (see Supplementary Material, Text S1); no landslides were identified as being triggered by earthquakes from this analysis.

\subsection{COST733 synoptic weather types and landslide occurrence}

The COST733 catalogue is a catalogue of synoptic weather in Europe. This catalogue has 5076 different classifications, each using one of 17 automated or five subjective methods of classification (Philipp et al. 2010). The classifications use one of 12 European Domains in Fig. 1b, in order to cover different spatial scales and regions; from the whole of Europe (D00) down to smaller regions such as the European Alps (D06; Philipp et al. 2010). Each of the 5076 classifications is divided into nine, 18 or 27 different weather types to capture the majority of variation in atmospheric circulation patterns across the year. There are also seasonal classifications which includes 28 weather types, with seven types for each season.

Brier Skill Scores (BSS) are a skill score used for the evaluation of binary probabilistic or ensemble forecasts (Brier 1950; Schiemann and Frei 2010), and were calculated for all classifications ( $n=5076$; including both yearly and seasonal classifications) across all domains (D00-D11) for landslide occurrence during the period 1970-2002. For the top five ranking COST733 classifications (identified by the BSS), Monte Carlo Permutation (MCP) tests were used to identify the number of days under each weather type with significantly $(p<0.01$, two- 
tailed test) greater than expected numbers of landslides (LsD), and those with significantly lower numbers (LLsD), seasonally. For this, 1000 random permutations were applied in which random dates during the period 1970-2002 were assigned to each landslide (providing a random sample of COST733 weather types for each permutation). In this, the number of landslides occurring under each weather type was calculated for each permutation, and $99 \%$ confidence intervals derived; observed landslide numbers from the inventory for each weather type were compared with these confidence intervals to test the hypothesis that landslides are more (or less) likely to occur under certain synoptic weather types than would be expected by chance.

\subsection{Trends in COST733 weather types and landsliding through time}

To test the hypothesis that the frequency of weather types associated with landsliding will have changed seasonally under a changing climate, weather types most commonly associated with increased landslide frequency (LsD; for each season) were selected. The frequency of the selected weather types were assessed for the period 1970-2002 using linear regression in order to analyse changes over time. The analysis was done only for the best performing classification and on a seasonal basis. Linear regression was also performed on landslide occurrence for the same period on a seasonal basis. The frequency of the selected weather types was also assessed over the duration of the COST733 catalogue (September 1957 to August 2002) in order to detect any changes in trend over this longer time period (results for this are given in the Supplementary Materials; Text S2).

\section{Results and discussion}

\subsection{COST733 synoptic weather types and landslide occurrence}

Overall, the majority of landslides recorded occurred during the spring (March/April/May; $\sim 29 \%$ ) and summer (June/July/August; $\sim 36 \%$ ), with the lowest numbers recorded during autumn (September/October/November; $\sim 15 \%$ ) and winter (December/January/February; $\sim 20 \%$ ). To overcome issues surrounding the use of a large dataset that includes many classification methods, Brier Skill Scores were used to assess the predictive ability of each of the 5076 different classifications. $67 \%$ of the top 100 COST733 classifications fell in domains centred over the European Alps and include all of the areas covered by the inventory (D06 and D07), with the remaining $33 \%$ falling in domains which included a portion of the landslide inventory (D09, D10 or D00; c.f. Figure 1a). The top 100 COST733 classifications were automated classifications, with $72 \%$ using a form of optimization classification (Philipp et al. 2010, 2014). The subjective Gross-Wetter types, usually used in Europe, ranked relatively highly whilst other subjective classifications (such as the Perret, Schüepp and Péczely) did not perform as well (Table 1); although less than $2 \%$ of the COST733 catalogue are subjective.

Of the different classification methods, those which include a seasonal component perform best (76 \% of the top 100), implying a strong seasonal signal in landslide frequency. The top five ranking classifications (based on the BSS) were all seasonal classifications (Table 1); therefore the MCP tests were run separately for each season. MCP tests carried out on the top five classifications highlight that a number of weather types have more landslides recorded 
Table 1 The results of the Brier Skill Score (BSS) analysis (1970-2002). The top classifications are all automated, while the best of the subjective classifications are highlighted in the shaded rows. Rank is based on the BSS result, name is from the COST733 catalogue

\begin{tabular}{|c|l|c|c|c|}
\hline Rank & COST733 classification (name) & $\begin{array}{c}\text { Classification } \\
\text { method }\end{array}$ & $\begin{array}{c}\text { Weather } \\
\text { types }(\boldsymbol{n})\end{array}$ & BSS \\
\hline 1 & CKM27_SE_S01_SP.K5.CKM28_SE_S01_SP.K5_D06 & CKMeans & 28 & 0.029 \\
\hline 2 & CKM27_SE_S01_SP.CKM28_SE_S01_SP_D06 & CKMeans & 28 & 0.029 \\
\hline 3 & CAP27_SE_S01_SP.CAP28_SE_S01_SP_D06 & $\begin{array}{c}\text { Cluster Analysis of } \\
\text { Principal components }\end{array}$ & 28 & 0.028 \\
\hline 4 & CAP27_SE_S01_SP.K5.CAP28_SE_S01_SP.K5_D06 & $\begin{array}{c}\text { Cluster Analysis of } \\
\text { Principal components }\end{array}$ & 28 & 0.028 \\
\hline 5 & $\begin{array}{l}\text { SAN27_SE_S01_SP.Z5.Y5.K5.SAN28_SE_S01_SP.Z5.Y5.K5 } \\
\text { D06 Simulated ANeilling } \\
\text { clustering }\end{array}$ & 28 & 0.028 \\
\hline 84 & GWT27_YR_S01_SP.GWT26_YR_S01_SP_D06.txt & GrossWetter & 27 & 0.022 \\
\hline 280 & PERo27_YR_S01_SP.PERo31_YR_S01_SP_D00.txt & Perret & 27 & 0.018 \\
\hline 439 & SUE027_YR_S01_SP.SUE040_YR_S01_SP_D00.txt & Schüepp & 27 & 0.017 \\
\hline 1750 & OGWo27_YR_S01_SP.OGW029_YR_S01_SP_D00.txt & $\begin{array}{c}\text { Objective } \\
\text { GrossWetter }\end{array}$ & 27 & 0.010 \\
\hline 2542 & PECo09_YR_S01_SP.PECo13_YR_S01_SP_D00.txt & Péczely & 9 & 0.008 \\
\hline
\end{tabular}

than would be expected; identifying weather types with anomalously high precipitation across the extent of the landslide inventory are associated with greater than expected numbers of landslides (LsD), whilst weather types with anomalously low precipitation were consistent with lower than expected numbers of landslides (LLsD) across all seasons (Figs. 2 and 3). There is also a noticeable difference in temperature between LsD and LLsD, with colder temperatures prevailing with higher landslide numbers, and the opposite for low landslide numbers.

The classification with the greatest skill was located in D06 (centred over the European Alps; Fig. 1a; Table 1), suggesting that the application of the BSS were effective. It is a seasonal classification with 28 weather types; seven types for each season. The classification uses a k-means algorithm, using dissimilar pressure fields (Philipp et al. 2010). The results of the MCP tests for this classification are representative across all of the top five ranking classifications (Table 1) and so only this top ranking classification for the period 1970-2002 will be considered in the following sections (the results for the period 1957-2002 can be found in Supplementary Materials Text S2).

During the summer, the Azores anticyclone (type \#15; Figure S2) is the most common weather type ( $>20 \%$ of days), but associated with comparatively few recorded landslides ( $<9 \%$ of days; Table 2 ). In comparison, the least frequently recorded weather type during the summer (type \#21; Table 2) had landslides recorded on $>20 \%$ of days, giving it the highest probability of landslides, with observed landslide numbers exceeding that which would be expected from the MCP analysis. This weather type follows a Meridional pattern, with an Azores anticyclone and central Europe low, associated with anomalously high precipitation over the Alps and colder than average temperatures (Fig. 2). A high number of landslides are also recorded under weather type \#16, despite a widespread low precipitation anomaly over central Europe (Figure S1; Table 2). This weather type has high mean sea level pressure over the Alps, combined with higher temperatures, and low pressure systems over the Mediterranean; 


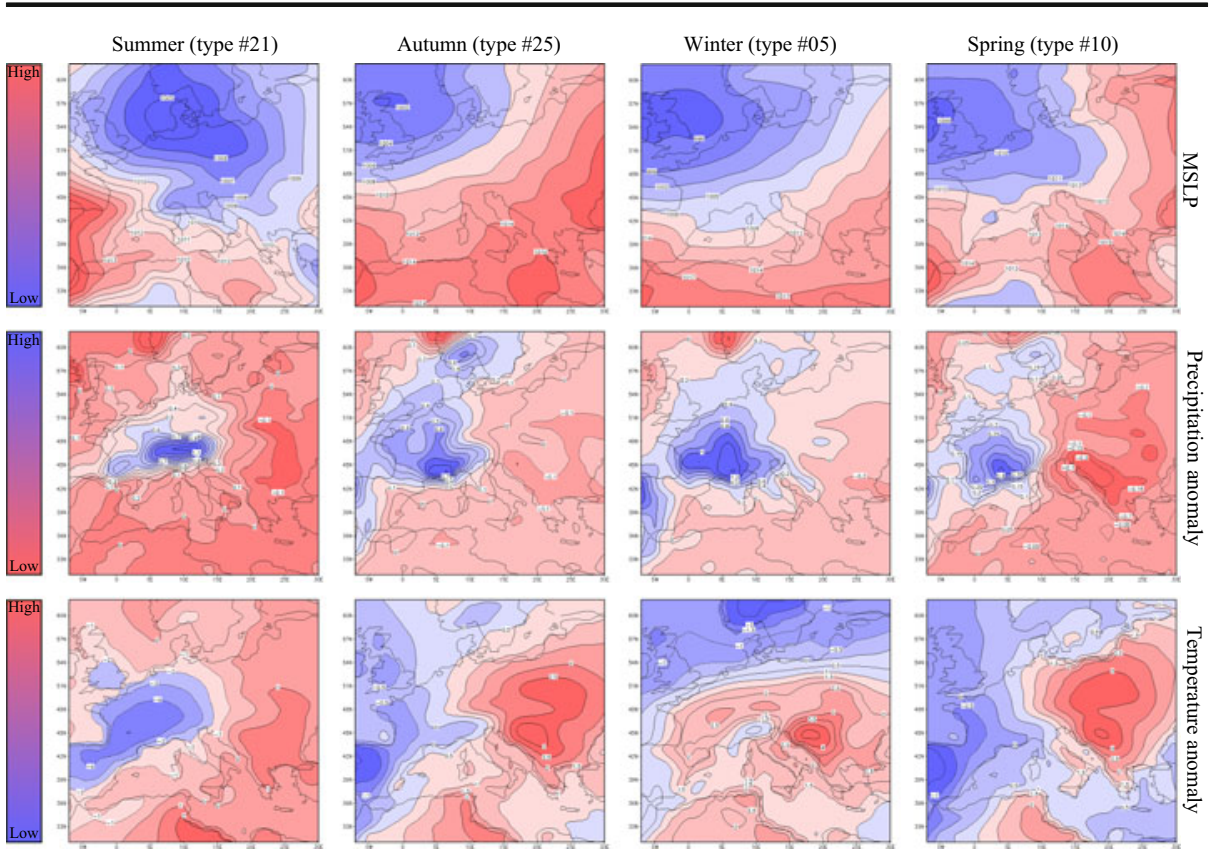

Fig. 2 COST733 weather types generated from the European ERA40 reanalysis dataset which are associated with the highest probability of a landslide (LsD) for each of the four seasons (based on the MCP analysis). (top) Mean sea level pressure (MSLP; with red indicating high pressure and blue, low), (middle) precipitation anomaly (blue areas indicate a positive anomaly whilst red, negative), (bottom) temperature anomaly (with red areas indicative of a positive temperature anomaly and blue a negative anomaly)

often associated with convective storms and heavy downpours in the region (Rudolph and Friedrich 2011; Stoffel et al. 2011) potentially causing the high landslide numbers observed. In contrast, the anticyclone over central Europe (type \#18; Fig. 3), is dominated by dryer than average conditions and warmer temperatures over the Alps, and is associated with low landslide numbers.

In spring there was one weather type associated with higher than expected landslides. More than $42 \%$ of landslides during spring $(n=373)$ were recorded under a westerly pattern (type \#10; Fig. 2), which brings anomalously high precipitation to the Alps. In contrast, the Azores anticyclone pattern (type \#08) includes $<13 \%$ of spring-time landslides, and features low precipitation over the region and higher than average temperatures (Fig. 3).

During the autumn months, around $60 \%$ of all landslides are recorded under westerly patterns (types \#25 and \#26). These are associated with anomalously high precipitation centred over the Alps, and lower than average temperatures (Figs. 2 and S1). In contrast to this, the central Europe blocking high (type \#24; Fig. 3) features anomalously low precipitation over the Alps and warmer temperatures, and includes $<3 \%$ of landslides recorded during the autumn.

During the winter, the majority of landslides ( $>60 \%$; Table 2$)$ were recorded under either winter westerlies (type \#05; Fig. 2) or a central Europe low (type \#06; Figure S1); both of which bring anomalously high precipitation to the Alps and lower than average temperatures. Around a quarter of landslides recorded in the winter occurred during the winter of 1990, and coincide with a heavy precipitation event (Isotta et al. 2014; see also Supplementary Text S3). Significantly low landslide numbers $(\sim 4 \%$ of the total) were recorded under a blocking high 


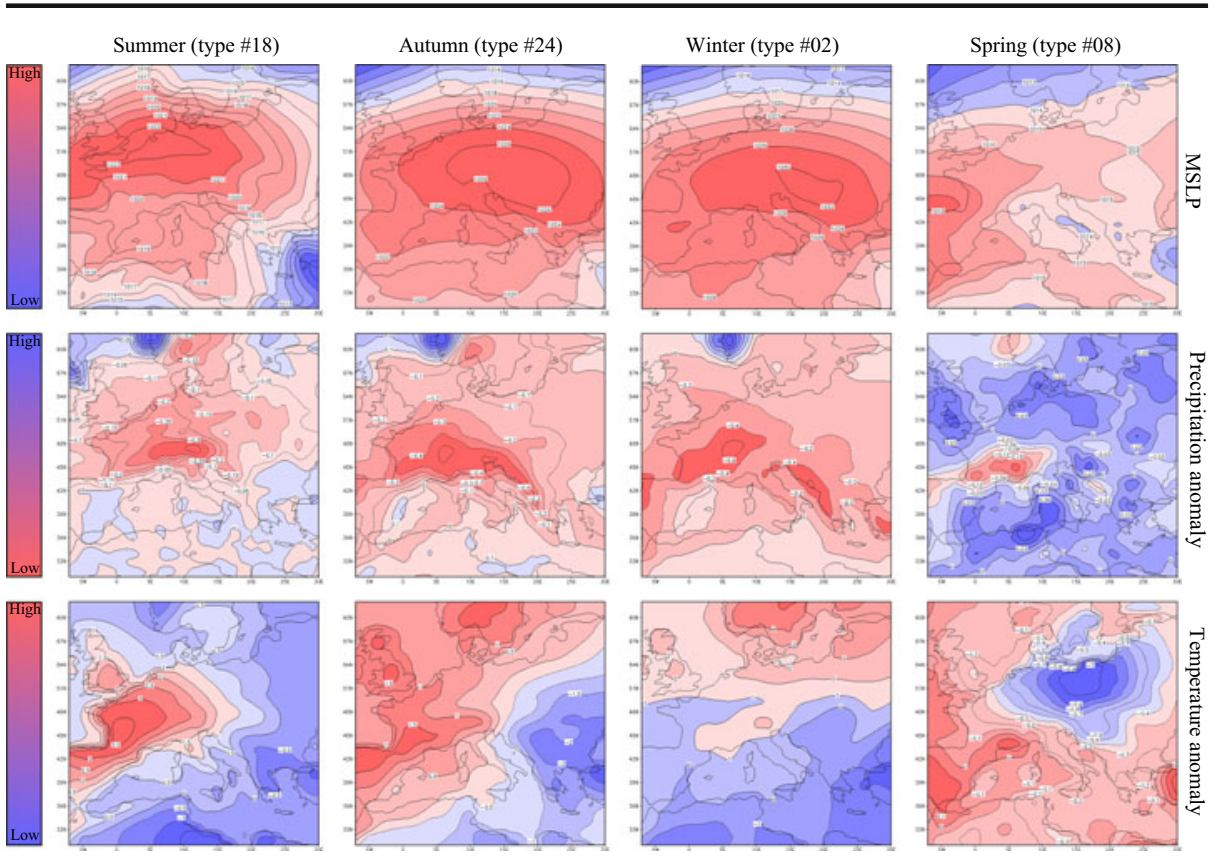

Fig. 3 COST733 weather types generated from the European ERA40 reanalysis dataset which are associated with a lower frequency of landslides days (LLsD) than would be expected (based on the MCP analysis). (top) Mean sea level pressure (MSLP; with red indicating high pressure and blue, low), (middle) precipitation anomaly (blue areas indicate a positive anomaly whilst red, negative), (bottom) temperature anomaly (with red areas indicative of a positive temperature anomaly and blue a negative anomaly)

(type \#02; Fig. 3), characterised by anomalously low precipitation and higher temperatures; consistent with other seasons.

For each season there was variation in weather types associated with higher than expected frequencies of landsliding; with higher precipitation anomalies being generally associated with higher frequencies of landsliding. It is possible for landslides that occurred in the morning, that the previous days weather type would have been more appropriate to use (the issue of antecedent conditions), however due to the persistence of the weather types, this should be a minor factor. It is also possible that the persistence of the weather types themselves are important, such as precipitation over several days, or anomalously warm temperatures in winter or spring. The analysis of weather types over multiple days is therefore an avenue for future research.

\subsection{Trends in COST733 weather types and landsliding through time}

Linear regression was used to detect changes through time in the frequency of the 28 weather types from the top ranking classification (Table 1). Only four weather types had either a significant decrease or increase in frequency (1970-2002; Table 3 and Fig. 4). During the spring and autumn months, an increase in recorded landslide numbers (Figure S5) is reflected in the decrease in the number of days associated with low landslide numbers (Fig. 4a). During the spring this specifically occurs with a significant decrease in the number of days associated with a central European low (type \#12; Table 3; Figs. 4a and S3). During the autumn, there has also been a general increase in the frequency of landslides (although not significantly), with the 


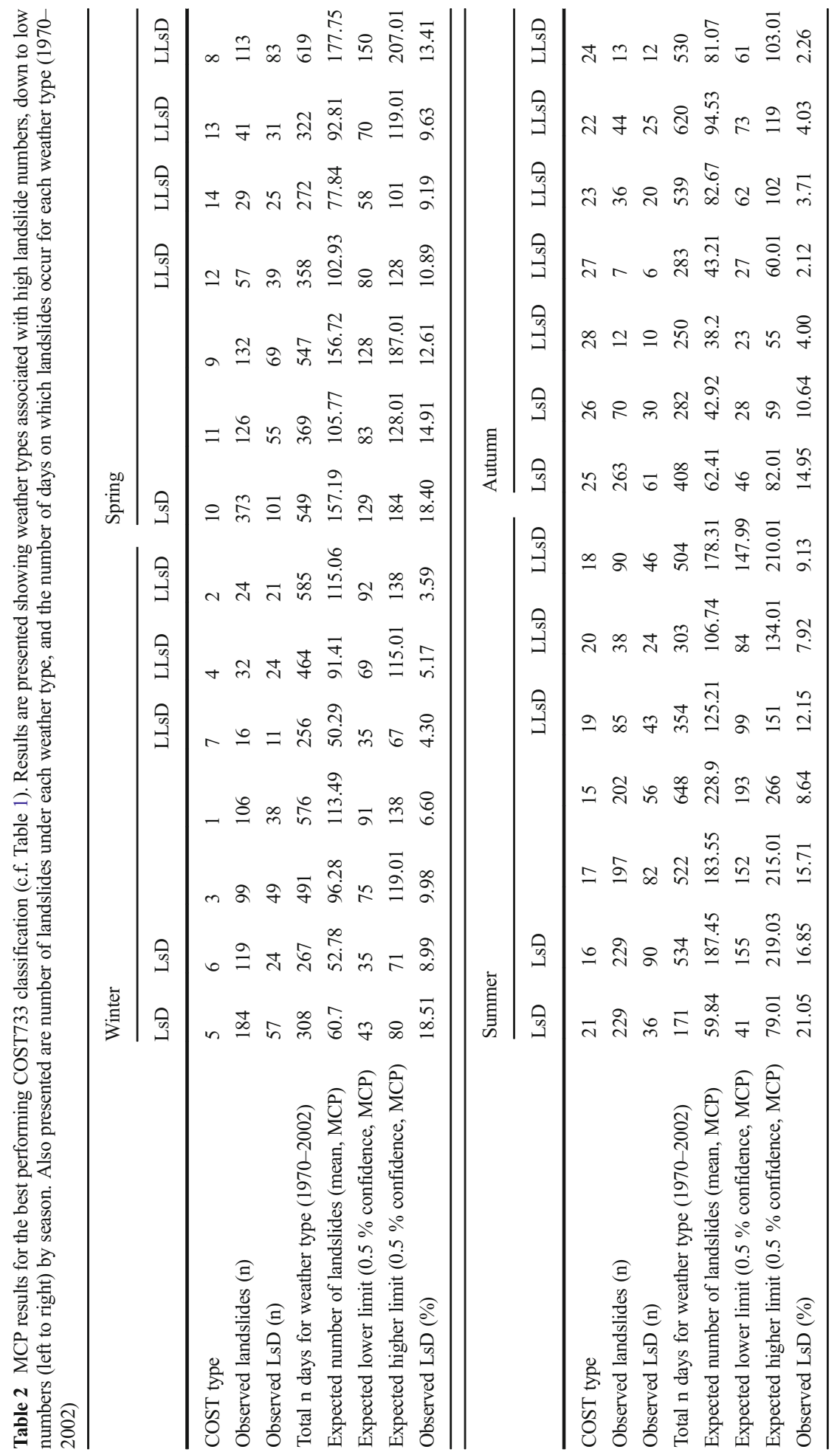


Table 3 Changes in the frequency of weather types, and seasonal landslide frequency for the period 1970-2002. The slope of the regression line is indicative of the observed trend. Significant changes $(p<0.05)$ are highlighted by the grey shading

\begin{tabular}{|c|c|c|c|c|c|c|}
\hline & \multicolumn{4}{|c|}{ COST733 trend $1970-2002$} & \multicolumn{2}{|c|}{$\begin{array}{l}\text { Seasonal } \\
\text { landslide }\end{array}$} \\
\hline & $\begin{array}{l}\text { Weather } \\
\text { type }(\#)\end{array}$ & Slope & $p$-value & \begin{tabular}{|l|} 
LsD/ \\
LLsD
\end{tabular} & Slope & $\begin{array}{c}p- \\
\text { value }\end{array}$ \\
\hline \multirow{7}{*}{ Winter } & 1 & -0.262 & 0.013 & & \multirow{7}{*}{0.835} & \multirow{7}{*}{0.102} \\
\hline & 2 & 0.007 & 0.972 & LLsD & & \\
\hline & 3 & 0.247 & 0.010 & & & \\
\hline & 4 & 0.193 & 0.078 & LLsD & & \\
\hline & 5 & -0.122 & 0.156 & LsD & & \\
\hline & 6 & -0.149 & 0.118 & LsD & & \\
\hline & 7 & -0.080 & 0.406 & LLsD & & \\
\hline \multirow{7}{*}{ Spring } & 8 & -0.155 & 0.197 & LLsD & \multirow{7}{*}{1.244} & \multirow{7}{*}{0.050} \\
\hline & 9 & 0.222 & 0.051 & & & \\
\hline & 10 & 0.141 & 0.141 & LsD & & \\
\hline & 11 & -0.085 & 0.379 & & & \\
\hline & 12 & -0.258 & 0.002 & LLsD & & \\
\hline & 13 & 0.205 & 0.079 & LLsD & & \\
\hline & 14 & -0.071 & 0.440 & LLsD & & \\
\hline \multirow{7}{*}{ Summer } & 15 & -0.071 & 0.406 & & \multirow{7}{*}{0.640} & \multirow{7}{*}{0.064} \\
\hline & 16 & 0.213 & 0.092 & LsD & & \\
\hline & 17 & -0.022 & 0.829 & & & \\
\hline & 18 & 0.059 & 0.583 & LLsD & & \\
\hline & 19 & -0.111 & 0.215 & LLsD & & \\
\hline & 20 & -0.095 & 0.291 & LLsD & & \\
\hline & 21 & 0.027 & 0.630 & LsD & & \\
\hline \multirow{7}{*}{ Autumn } & 22 & -0.183 & 0.216 & LLsD & \multirow{7}{*}{0.071} & \multirow{7}{*}{0.868} \\
\hline & 23 & 0.012 & 0.926 & LLsD & & \\
\hline & 24 & -0.310 & 0.019 & LLsD & & \\
\hline & 25 & 0.193 & 0.129 & LsD & & \\
\hline & 26 & -0.040 & 0.657 & LsD & & \\
\hline & 27 & -0.035 & 0.682 & LLsD & & \\
\hline & 28 & -0.123 & 0.152 & LLsD & & \\
\hline
\end{tabular}

majority of weather types associated with low landslide numbers having decreased (Table 3). In particular, the central Europe blocking high (type \#24) has significantly decreased in frequency for the period 1970-2002 (Fig. 4a).

During the winter months, winter westerlies are represented by two weather types (both associated with an expected number of landslides based on the MCP analysis); type \#03, featuring warmer temperatures over the Alps and negative precipitation anomaly and type \#01, also with warmer temperatures, but with a high precipitation anomaly over the Alps (Figure S2). 

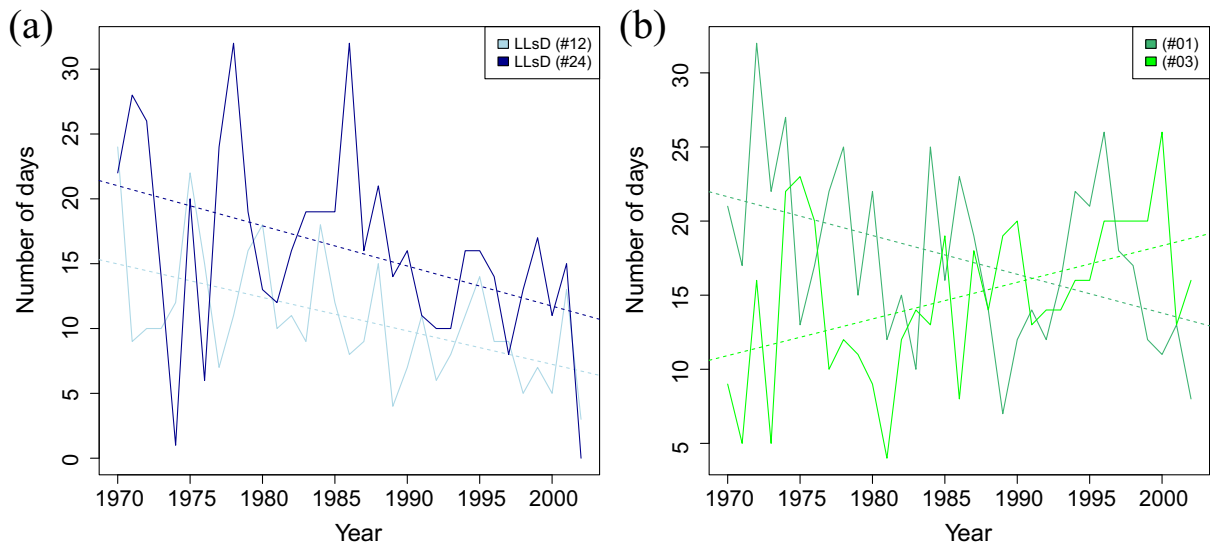

Fig. 4 Significant changes in the frequency of weather types for (a) weather types associated with lower than expected recorded landslide numbers and (b) weather types associated with expected numbers of recorded landslides (not LsD or LLsD) for the period 1970-2002

The frequency of type \#03 has significantly increased (Fig. 4b and Table 3) (consistent with the 1957-2002 trend; Table S2), while the frequency of type \#01 has significantly decreased. During the winter months there has been an overall increase in the number of landslides recorded between 1970 and 2002 (Figure S5) whilst weather types (\#05 and \#06) associated with high landslide numbers, have been decreasing in frequency and types associated with low landslide numbers have been increasing (types \#02 and \#04; Table 3). This disjuncture between observation (of landslides) and inference (of more or less landslides) based on trends in weather patterns, highlights the importance of additional factors that predispose a slope to landslides, such as antecedent weather conditions, local geology and topography. Considering weather patterns on the day of failure is instructive but limited in its predictive ability without consideration of these additional factors.

\section{Conclusions}

We have demonstrated a relationship between synoptic weather and the incidence of landslides in the European Alps, and have shown that a number of weather types are related to a higher than expected number of landslides in the region. We found that weather types with patterns of high precipitation across the Alps were consistent with higher numbers of recorded landslides across all seasons, demonstrating that synoptic weather types can be effectively used as predictors of landslide occurrence. Precipitation patterns are hard to predict at the small-scale, particularly when considering future predictions under a changing climate. Precipitation, particularly extreme events, is less well constrained in climate models than temperature (e.g. Beniston et al. 2007; Kjellström et al. 2011; Gobiet et al. 2014) and the use of weather types presents an alternative approach to these challenges posed as well as the potential for weather typing being used as a predictive tool for landslide events under differing future climate scenarios.

We have shown that over the duration of the COST733 catalogue, the number of days associated with different weather types has fluctuated over time and this has the potential to change in the future with the changing climate. Based on the analyses presented here, 
landslides have been shown to occur under all weather types, but are more likely under some weather types; with westerly patterns resulting in higher landslide frequencies from autumn to spring, and a Meridional pattern, with an Azores anticyclone and central Europe low weather during the summer months. Furthermore, while recent trends in summer landslides are wellmatched with trends in weather types associated with higher landslide numbers, there is a mismatch for winter weather types and winter landslides; this could be due to snow cover acting as a stabilising factor. It is clear that other factors (such as rainfall persistence, geology and topography) play an important role which we hope to address in future research. The role of large-scale climatic systems such as the North Atlantic Oscillation the issue of antecedence are also fruitful avenues for future research.

Acknowledgments We would like to thank M. Stoffel and two anonymous referees for their helpful comments. We thank Lloyd's of London for funding this research. The COST733 catalogues are freely available online from http://cost733.met.no/ and we would like to thank Andreas Philipp, Christophe Beck and Ole Einar Tveito for their cooperation and assistance. The USGS earthquake data is available online from: http://earthquake.usgs.gov/ earthquakes/search/. We would also like to thank Francesco Isotta for providing Figure S4 of this paper.

Open Access This article is distributed under the terms of the Creative Commons Attribution 4.0 International License (http://creativecommons.org/licenses/by/4.0/), which permits unrestricted use, distribution, and reproduction in any medium, provided you give appropriate credit to the original author(s) and the source, provide a link to the Creative Commons license, and indicate if changes were made.

\section{References}

Barnard PL, Owen LA, Sharma MC, Finkel RC (2001) Natural and human-induced landsliding in the garhwal Himalaya of northern India. Geomorphology 40:21-35

Beniston M, Stephenson DB, Christensen OB, Ferro CAT, Frei C, Goyette S, Halsnaes K, Holt T, Jylhä K, Koffi B, Palutikof J, Schöll R, Semmler T, Woth K (2007) Future extreme events in European climate: an exploration of regional climate model projections. Clim Chang 81:71-95. doi:10.1007/s10584-006-9226-Z

Boé J, Terray L (2008) A weather-type approach to analysing winter precipitation in France: twentieth-century trends and the role of anthropogenic forcing. J Clim 21:3118-3133

Borgatti L, Soldati M (2010) Landslides as a geomorphological proxy for climate change: a record from the dolomites (Northern Italy). Geomorphology 120:56-64

Brier GW (1950) Verification of forecasts expressed in terms of probability. Mon Weather Rev 78:1-3

Chemenda A, Bouissou S, Bachmann D (2005) Three-dimensional physical modelling of deep-seated landslides: new technique and first results. J Geophys Res Earth Surf 110. doi:10.1029/2004JF000264

Conway D, Jones PD (1998) The use of weather types and air flow indices for GCM downscaling. J Hydrol 212213:348-361

Crozier MJ (2010) Deciphering the effect of climate change on landslide activity. Geomorphology 124:260-267

Dehn M, Buma J (1999) Modelling future landslide activity based on general circulation models. Geomorphology 30:175-187

Dramis F, Govi M, Mortara G (1995) Mountain permafrost and slope instability in the Italian Alps: the Val Pola landslide. Permafr Periglac Process 6:73-82

Farahmand A, AghaKouchak A (2013) A satellite-based global landslide model. Nat Hazards Earth Syst Sci 13: 1259-1267

Gariano SL, Brunetti MT, Iovine G, Melillo M, Peruccacci S, Terranova O, Vennari C, Guzzetti F (2015) Calibration and validation of rainfall thresholds for shallow landslide forecasting in Sicily, southern Italy. Geomorphology 228:653-665

Gobiet A, Kotlarski S, Beniston M, Heinrich G, Rajczak J, Stoffel M (2014) 21st century climate change in the European Alps - A review. Sci Total Environ 493:1138-1151

Guzzetti F, Peruccacci S, Rossi M, Stark CP (2007) Rainfall thresholds for the initiation of landslides in central and Southern Europe. Meteorog Atmos Phys 98:239-267

Isotta FA, Frei C, Weilguni V, et al. (2014) The climate of daily precipitation in the Alps: development and analysis of a high-resolution grid dataset from pan-alpine rain-gauge data. Int J Climatol 34:1657-1675

Iverson RM (2000) Landslide triggering by rain infiltration. Water Resour Res 36:1897-1910 
Jakob M, Weatherly H (2003) A hydroclimatic threshold for landslide initiation on the North Shore Mountains of Vancouver, British Columbia. Geomorphology 54:137-156

Keefer DK (2002) Investigating landslides caused by earthquakes - a historical review. Surv Geophys 23: 473-510

Keefer DK, Larsen MC (2007) Assessing landslide hazards. Science 316:1136-1138

Keiler M, Knight J, Harrison S (2010) Climate change and geomorphological hazards in the Eastern European Alps. Phil Trans R Soc A 368:2461-2479

Kjellström E, Nikulin G, Hansson U, Strandberg G, Ullerstig A (2011) 21st century changes in the European climate: uncertainties derived from an ensemble of regional climate model simulations. Tellus A 63:24-40

Lopez Saez J, Corona C, Stoffel M, Berger F (2013) Climate change increases frequency of shallow spring landslides in the French Alps. Geology 41(5):619-622

Malamud BD, Turcotte DL, Guzzetti F, Reichenbach P (2004) Landslides, earthquakes, and erosion. Earth Planet Sci Lett 229:45-59

Malet J-P, Glade T, Casagli N (2010) The "safeland" project: living with landslide risk in Europe. In: Malet, Glade, Casagli (Eds.), Mountain Risks: Bringing Science to Society, pp 523-558

Marques R, Zêzere J, Trigo R, Gaspar J, Trigo I (2008) Rainfall patterns and critical values associated with landslides in Povoaçao County (Sao Miguel Island, Azores): relationships with the North Atlantic Oscillation. Hydrol Process 22:478-494

Meunier M, Hovius N, Haines J (2008) Topographic site effects and the location of earthquake induced landslides. Earth Planet Sci Lett 275:221-232

Nikolopoulos EI, Borga M, Marra F, Crema S, Marchi L (2015) Debris flows in the Eastern Italian Alps: seasonality and atmospheric circulation patterns. Nat Hazards Earth Syst Sci 15:647-656. doi:10.5194/ nhess-15-647-2015

Paredes R, Trigo M, Garcia-Herrera R, Franco Trigo I (2006) Understanding precipitation changes in Iberia in Early Spring: Weather Typing and Storm-Tracking Approaches. J Hydrometeorol 7:101-113

Peruccacci S, Brunetti MT, Luciani S, Vennari C, Guzzetti F (2012) Lithological and seasonal control on rainfall thresholds for the possible initiation of landslides in Central Italy. Geomorphology 139-140:79-90

Philipp A, Bartholy J, Beck C, et al. (2010) Cost733cat - A database of weather and circulation type classifications. Phys Chem Earth 35:360-373

Philipp A, Beck C, Esteban P, Kreienkamp F, Krennert T, Lochbihler K, Lykoudis SP, Pianko-Kluczynska K, Post P, Rasilla Álvarez D, Spekat A, Streicher F (2014) Cost733class-1.2 User guide. Available from http:// cost733.geo.uni-augsburg.de/download/cost733class-1.2/cost733class_userguide.pdf

Rudolph JV, Friedrich K (2011) Relationship between radar-estimated precipitation and synoptic weather patterns in the European Alps. J Appl Meteorol Climatol 50:944-957

Schiemann R, Frei C (2010) How to quantify the resolution of surface climate by circulation types: An example for alpine precipitation. Phys Chem Earth 35:403-410

Stoffel M, Bollschweiler M, Beniston M (2011) Rainfall characteristics for periglacial debris flows in the Swiss Alps: past incidences-potential future evolutions. Clim Chang 105:263-280

Stoffel M, Tiranti D, Huggel C (2014) Climate change impacts on mass movements - case studies from the European Alps. Sci Total Environ 493:1255-1266

Uppala SM, Kållberg PW, Simmons AJ, et al. (2005) The ERA-40 re-analysis. Q J R Meteorol Soc 131:2961-3012 Varnes DJ (1978) Slope movement types and processes. In: Schuster RL, Krizek RJ (eds) Special report 176 landslides: analysis and control. Transportation Research Board, National Research Council, Washington D.C., pp. 11-33

Wood JL, Harrison S, Reinhardt L (2015) Landslide inventories for climate impacts research in the European Alps. Geomorphology 228:398-408

Zêzere JL, Trigo RM, Trigo IF (2005) Shallow and deep landslides induced by rainfall in the Lisbon region (Portugal): assessment of relationships with the North Atlantic oscillation. Nat Hazards Earth Syst Sci 5: 331-344 